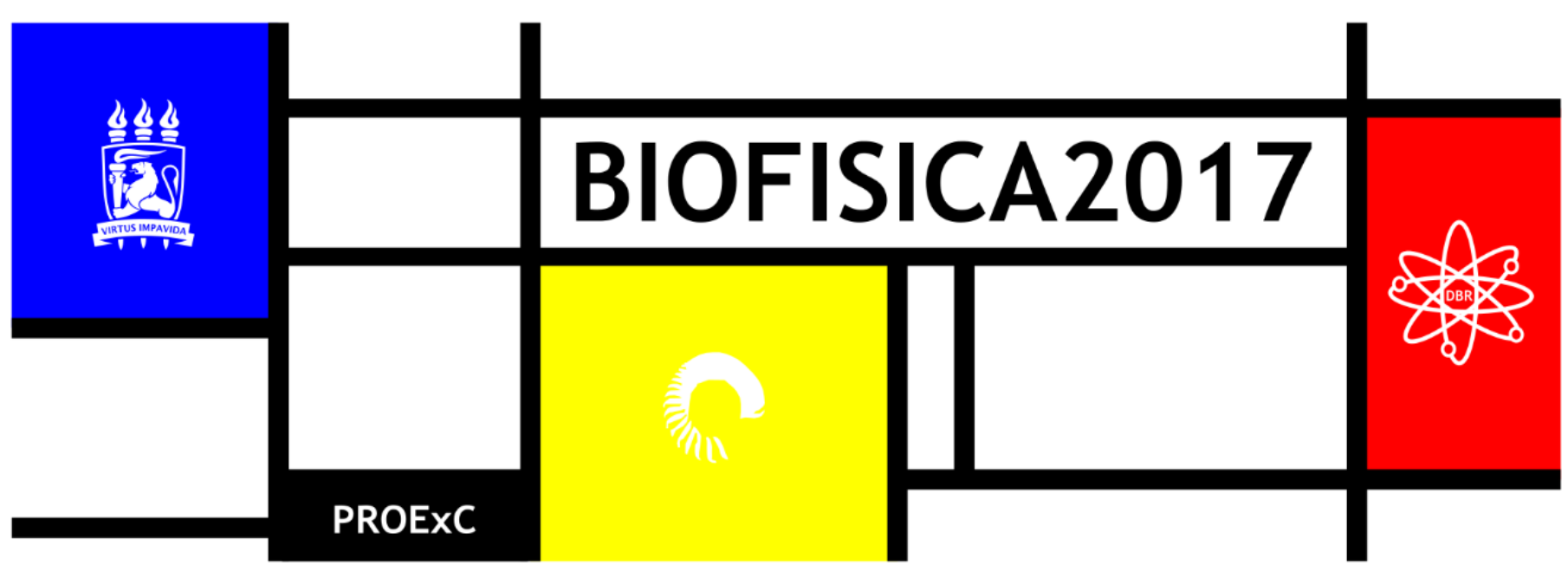

\title{
QUANTIFICAÇÃO DE LANTÂNIO POR EDXRF EM SOLOS E SEDIMENTOS TROPICAIS
}

\author{
${ }^{1}$ CRCN-NE/CNEN \\ *email: thiago_cbufpe@yahoo.com.br
}

Thiago Oliveira dos Santos ${ }^{1 *}$, Mechele da Silva Santos ${ }^{1}$, Elvis Joacir De França ${ }^{1}$

\section{INTRODUÇÃO}

Elementos terras raras formam um grupo de elementos químicos com características e propriedades semelhantes. Encontrados em mais de 250 minérios são amplamente utilizados como matériaprima insubstituível para a tecnologia de ponta (Westin, 2013). Um dos elementos químicos de menor peso atômico do grupo terras raras é o lantânio. Por meio da quantificação deste elemento químico é possível construir um modelo de predição para os demais elementos do grupo. Das técnicas analíticas utilizadas para quantificação deste elemento químico a Fluorescência de Raios-X por Dispersão de Energia é a menos difundida. Esta baseia-se na medida das intensidades dos raios- $X$ característicos emitidos pelos elétrons excitados de uma determinada amostra. Como principais vantagens associadas a essa técnica analítica é destacada a dispensa de dissolução química das amostras, proporcionando resultados de forma mais rápida e a um baixo custo. Entretanto, as análises não podem ser realizadas de maneira generalizada; cada amostra deve ser avaliada com base em curvas previamente constituídas com materiais de referência certificados. Este trabalho tem por objetivo o estabelecimento de curva analítica para a quantificação de lantânio em solos e sedimentos tropicais por meio da técnica EDXRF.

\section{MATERIAL E MÉTODOS}

\section{EDXRF}

Amostras acondicionadas em recipientes específicos são submetidas a um feixe de raios- $X$ ocasionando a excitação dos elétrons dos átomos presentes nas amostras. Esses elétrons excitados emitem raios- $X$ característicos que são medidos por um detector semicondutor. 0 sinal é amplificado e o espectro de raios$X$ analisado em um software específico para identificação dos elementos químicos presentes na amostra a partir de suas linhas de energia (Figura 1). Desta maneira, é possível realizar análises qualitativas e quantitativas a partir de curvas de calibração previamente construídas (ANJOS et al., 2002; MARGUÍ et al., 2005; JOSHI et al., 2006; SOUSA et al., 2013).

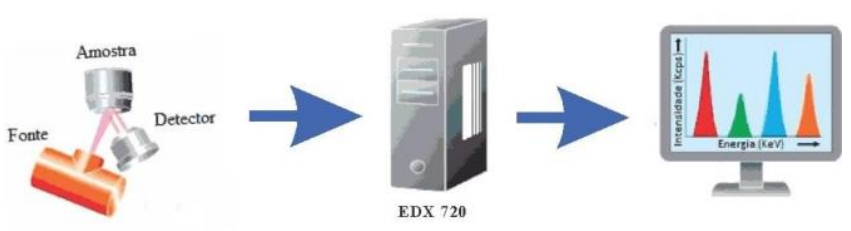

Figura 1. Metodologia de análise por EDXRF .

Preparação e análise dos materiais de referência

Porções teste de aproximadamente $0,5 \mathrm{~g}$ foram acondicionadas em cápsulas de polietileno cilíndricas e vedadas com filme de polipropileno específico para análise por EDXRF. As análises foram realizadas no espectrômetro EDX 720 da Shimadzu, sob atmosfera com pressão menor que $30 \mathrm{~Pa}$ e a tensão de $15 \mathrm{kV}$ utilizada para a determinação do elemento químico La (Figura 2). Todas as medidas foram realizadas em triplicata.

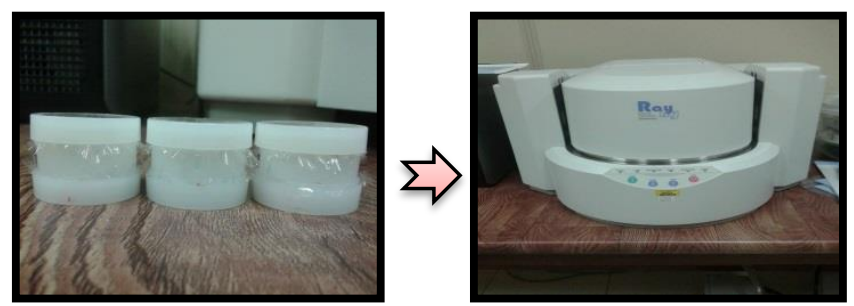

Figura 2. Cápsulas preparadas para análises e equipamento EDXRF.

\section{Curva analítica}

Inicialmente foram desenvolvidos testes com os filtros de alumínio, molibdênio, molibdênio/níquel, prata e titânio, com o objetivo de reduzir a influência de elementos com níveis de energia similares ao do lantânio. Dentre os filtros estudados o de Ti demonstrou-se mais apropriado para as análises. Após a seleção do filtro, foi construída a curva analítica para quantificação de La em matrizes geológicas utilizando os materiais de referência SRM 2710, SRM 1944, IAEA-SL-1 e IAEA-SOIL-7. 


\section{RESULTADOS E DISCUSSÃO}

Com a nova curva analítica foi possível otimizar a metodologia de análise utilizada no Serviço de Monitoração Ambiental (SEAMB) do Centro Regional de Ciências Nucleares do Nordeste (CRCN/NE) para a quantificação de La por EDXRF (Figura 3).

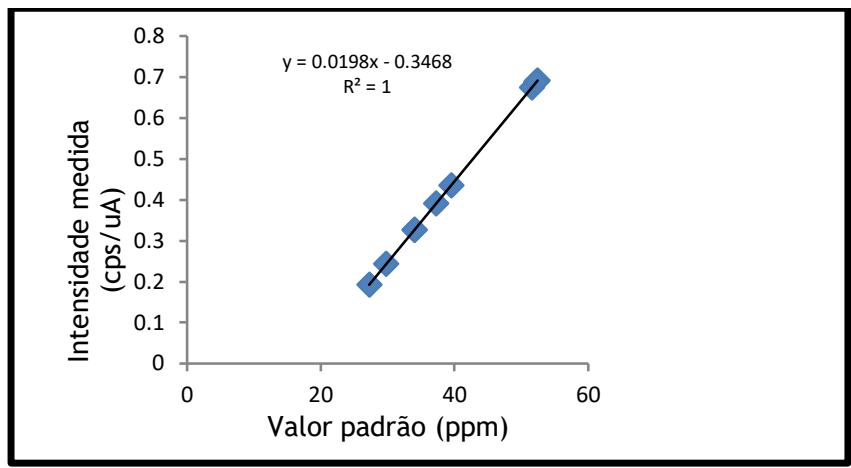

Figura 3 - Curva analítica para análise de lantânio por EDXRF.

Para avaliar a qualidade do procedimento analítico foram analisados os materiais de referência IAEA Soil 7 e SRM 2710. Os valores observados e aqueles de referência são apresentados na Tabela 1.

Tabela 1. Concentrações médias de valores observados e certificados, intervalos de confiança e incertezas expandias em nível de significância de 95\% para Lantânio obtidas utilizando a nova curva analítica do EDXRF.

\begin{tabular}{ccc}
\hline $\begin{array}{c}\text { Material de } \\
\text { Referência }\end{array}$ & $\begin{array}{c}\text { Valor de referência } \\
(\mathrm{mg} . \mathrm{kg}-1)\end{array}$ & $\begin{array}{c}\text { Valor observado } \\
(\mathrm{mg} \cdot \mathrm{kg}-1)\end{array}$ \\
\hline SRM 2710 & 34 & $34 \pm 6$ \\
IAEA Soil 7 & $28(27-29)$ & $28 \pm 5$ \\
\hline
\end{tabular}

A qualidade do procedimento analítico foi comprovada a partir dos resultados obtidos para os materiais de referência em nível de 95\% de confiança.

\section{CONCLUSÕES}

Com a nova curva analítica foi possível otimizar o protocolo analítico reduzindo-se as interferências espectrais para a realização da determinação de La por EDXRF em matrizes geológicas.

\section{REFERÊNCIAS}

ANJOS, M. J.; LOPES, R. T.; JESUSB, E. F. O.; ASSISC, J. T.; CESAREOD, R.; BARROSA, R. C.; BARRADASE, C. A. A. Elemental concentration analysis in soil contaminated with recyclable urban garbage by tube-excited energy-dispersive $X$-ray fluorescence. Radiation Physics and Chemistry, v. 65, p. 495-500, 2002.

JOSHI, G. C.; AGRAWAL, H. M.; MOHANTA, B.; SUDARSHAN, M.; SINHA; A. K. Elemental study of Nainital Lake water by EDXRF. Nuclear Instruments and Methods in Physics Research B, v.251, p. 223-226, 2006.

MARGUÍ, E.; QUERALT, I.; CARVALHO, M. L.; HIDALGO, M. Comparison of EDXRF and ICP-OES after microwave digestion for element determination in plant specimens from an abandoned mining area. Analytica Chimica Acta, v. 549, p. 197-204, 2005.

SOUSA, E. E.; PAIVA, J. D. S.; FRANÇA, E. J.; ALMEIDA, M. E. S.; CANTINHA, R. S.; HAZIN, C. A. Qualidade nas análises químicas de matrizes biológicas pela fluorescência de raios-X por dispersão de energia. International Nuclear Atlantic Conference - INAC 2013. Recife, 2013. 1 DVD-Rom.

WESTIN, R. Brasil entre na corrida pelas terras-raras, Jornal do Senado, Brasília,15 abril. 2013. C\&T, p. 4-5. 